Samuel M. Barst MD FAAP, * Jonathan U. Leiderman $\mathrm{MD}$, * Avram Markowitz MD, * Abby M. Rosen MS RPH, $\dagger$ Allan L. Abramson MD FACS, $\ddagger$ Robert S. Bienkowski PhDS

\title{
Ondansetron with propofol reduces the incidence of emesis in children following ton- sillectomy
}

Purpose: This study tested the hypothesis that the antiemetic effects of a combination of ondansetron and propofol were superior to propofol alone in children undergoing tonsillectomy surgery.

Methods: A prospective, randomized, double-blind, placebo-controlled study design was employed. Young children underwent mask induction with halothane, nitrous oxide and oxygen and then had iv access established: older children had $i v$ induction with propofol. All patients received $0.3 \mathrm{mg} \cdot \mathrm{kg}^{-1}$ mivacurium and $2-4 \mu \mathrm{g}^{-\mathrm{kg}^{-1}}$ fentanyl iv and $30 \mathrm{mg}^{\mathrm{kg}} \mathrm{g}^{-1}$ acetaminophen pr to a maximum dose of $650 \mathrm{mg}$. Following induction, patients received either $100 \mu \mathrm{g} \cdot \mathrm{kg}^{-1}$ ondansetron or placebo. Anaesthesia was maintained with $120-140 \mu \mathrm{g} \cdot \mathrm{kg}^{-1} \cdot \mathrm{min}^{-1} \mathrm{propofol}$, nitrous oxide and oxygen to maintain vital signs within $20 \%$ of baseline. After surgery, in all patients the tracheas were extubated in the operating room without use of neuromuscular reversing agents. Episodes of emesis were recorded by PACU nurses for four to six hours. A telephone interview on the following day was also used for data recovery. Groups were compared in relation to age using the Mann-Whitney test, and with respect to sex and number of episodes of vomiting using the Fisher Exact Test.

Results: Three of the 45 patients who received ondansetron vomited (6.7\%), whereas 10 of the 45 patients who received placebo vomited $(22.2 \%) .(P=0.035)$

Conclusion: Ondansetron in a dose of $100 \mu \mathrm{g} \cdot \mathrm{kg}^{-1}$, when combined with propofol for children undergoing tonsillectomy reduced the incidence of postoperative vomiting to very low levels.

Objectif : Vérifier l'hypothèse voulant que les effets antiémétiques d'une combinaison d'ondansétron et de propofol soit supérieure à ceux du propofol seul chez des enfants qui subissent une amygdalectomie.

Méthode : On a utilisé une étude prospective, randomisée et en double aveugle contre placebo. Chez les jeunes enfants, l'induction au masque s'est faite avec de l'halothane et un mélange de protoxyde d'azote et d'oxygène, et on a établi ensuite l'accès iv ; chez les enfants plus âgés, c'était une induction iv avec du propofol. Tous les patients ont reçu $0,3 \mathrm{mg} \cdot \mathrm{kg}^{-1}$ de mivacurium et $2-4 \mu \mathrm{g} \cdot \mathrm{kg}^{-1}$ de fentanyl iv et $30 \mathrm{mg} \cdot \mathrm{kg}^{-1}$ d'acétaminophène pr jusqu'à une dose maximale de $650 \mathrm{mg}$. Après l'induction, les patients ont reçu soit $100 \mu \mathrm{g}^{\prime} \mathrm{kg}^{-1}$ d'ondansétron ou un placebo. L'anesthésie a été maintenue avec $120-140 \mu \mathrm{g} \cdot \mathrm{kg}^{-1} \cdot \mathrm{min}^{-1}$ de propofol et d'un mélange de protoxyde d'azote et d'oxygène pour conserver les signes vitaux à $\pm 20 \%$ des mesures de base. Après la chirurgie, on a extubé tous les patients dans la salle d'opération sans utiliser de décurarisant. Les épisodes de vomissements ont été notés pour une période de $4-6 \mathrm{~h}$ par les infirmières de la salle de réveil. Le jour suivant, une interview téléphonique a aussi fourni des données sur la récupération. On a comparé les groupes selon l'âge par le test de Mann-Whitney et selon le sexe et le nombre d'épisodes de vomissements par le test exact de Fisher.

Résultats : Trois patients sur 45 qui ont reçu de l'ondansétron ont eu des vomissements (6,7 \%), mais 10 patients sur 45 qui avaient reçu le placebo $(22,2 \%)$. $(P=0,035)$

Conclusion : Une dose de $100 \mu \mathrm{g} \cdot \mathrm{kg}^{-1} \mathrm{~d}^{\prime}$ ondansétron combinée à du propofol et administrée à des enfants lors d'une amygdalectomie a réduit l'incidence postopératoire de vomissements à de très bas niveaux.

From the Departments of Anesthesiology, ${ }^{*}$ Otolaryngology, $\dagger$, Pharmacy, $\ddagger$ and Pediatrics, $\$$ Schneider Children’s Hospital, Long Island Jewish Medical Center, The Long Island Campus for the Albert Einstein College of Medicine, New Hyde Park, New York 11040, USA. Address correspondence to: Samuel M. Barst MD, Division of Pediatric Anesthesiology, Schneider Children's Hospital, Long Island Jewish Medical Center, New Hyde Park, NY 11040 USA. Phone: 718-470-7390; Fax: 718-470-6307; E-mail: barst@lij. edu Accepted for publication January 17, 1999 
$\mathrm{T}$

ONSILLECTOMY is one of the most commonly performed outpatient surgical procedures in children and is associated with a $40-70 \%$ incidence of post-operative vomiting. ${ }^{1}$ Persistent vomiting and poor oral fluid intake are the most frequent complications and the leading causes of unscheduled overnight admission following tonsillectomy. ${ }^{2}$ Postoperative vomiting can delay discharge from the Ambulatory Surgical Unit (ASU) and persistent vomiting is potentially dangerous because it can lead to fluid depletion and dehydration and increase postoperative morbidity.

We recently reported a decrease in post-tonsillectomy vomiting from $55 \%$ to $22 \%$ by utilizing a propofol-based anesthetic instead of a gaseous agent and without using antiemetic agents. ${ }^{3}$ Two separate studies have demonstrated that the serotonin antagonist ondansetron reduced the incidence of post-tonsillectomy vomiting from $>60 \%$ to $<30 \%$. In those studies, the primary anesthetic agent was either halothane or isoflurane. ${ }^{5}$

In this study we hypothesized that the antiemetic effects of a combination of ondansetron and propofol would be superior to propofol alone. We performed a randomized, double-blind, placebo-controlled trial to test this hypothesis.

\section{Methods}

The study was approved by the Human Subjects Review Committee of The Long Island Jewish Medical Center. Written informed consent was obtained from the parents of 92 children, ASA physical status I or II, between one and eighteen years of age undergoing tonsillectomy, with or without adenoidectomy. Children were excluded from this study if they had a history of adverse reaction or allergy to any of the proposed study drugs or pronounced motion sickness.

Children received only clear fluids after midnight until three hours prior to surgery. The children were not premedicated. Most younger children were accompanied to the operating room by a parent. Most patients $<12$ yr of age had mask induction of anesthesia with $\mathrm{N}_{2} \mathrm{O}(70 \%), \mathrm{O}_{2}(30 \%)$ and increasing concentrations of halothane. Once a patient was anesthetized, an iv fluid infusion was established and the halothane was discontinued. Patients $>8 \mathrm{yr}$ of age had $i v$ induction with propofol. Both groups then received $0.3 \mathrm{mg} \cdot \mathrm{kg}^{-1}$ mivacurium and 2-4 $\mu \mathrm{g} \cdot \mathrm{kg}^{-1}$ fentanyl $i v$, and 30 $\mathrm{mg} \cdot \mathrm{kg}^{-1}$ acetaminophen $\mathrm{pr}$ (to a maximum dose 650 $\mathrm{mg})$. After establishment of neuromuscular blockade, an endotracheal tube was inserted and the lungs were mechanically ventilated. Anesthesia was maintained with a continuous infusion of $120-140 \mu \mathrm{g} \cdot \mathrm{kg}^{-1} \cdot \mathrm{min}^{-1}$ propofol with $\mathrm{N}_{2} \mathrm{O}(70 \%), \mathrm{O}_{2}(30 \%)$ in order to maintain vital signs within $20 \%$ of baseline values. Neuromuscular block was maintained with supplemental mivacurium as clinically indicated.

Patients were randomized at the time of enrollment in the study to receive either $0.1 \mathrm{mg} \cdot \mathrm{kg}^{-1}$ ondansetron $i v$ or placebo (normal saline) which was administered after intravascular access was established and prior to the start of the procedure. The study physician and patient were blinded to the agent being administered. The randomization procedure was a fixed block design and it was carried out as follows as follows: The study drugs were supplied to the anesthesiologist in vials provided by the hospital pharmacy. The vials were labeled A, B, C, and D; two of the vials contained 25 $\mathrm{ml}$ ondansetron and two contained $25 \mathrm{ml}$ normal saline. Ondansetron and saline were indistinguishable in appearance. Before the study, the letters A, B, C, or $D$ were written on 25 cards (for a total of 100 cards); the cards were shuffled extensively and each was placed inside a small envelope which was then placed inside a large envelope; then the envelopes were shuffled extensively. As each patient was entered into the study, the anesthesiologist drew one envelope and administered the liquid (medication or placebo) according to the letter code.

Patients received ip Plasma-Lyte A for fluid maintenance and to restore the calculated fasting deficit as well as to compensate for measured blood loss. At the end of surgery, gastric contents were evacuated in all patients. At the surgeon's discretion, some patients $(72 \%)$ received bupivacaine $(0.25 \%)$ injected into the tonsillar bed; the rates of bupivicaine administration did not differ between the groups. Neuromuscular function was allowed to recover spontaneously in all patients; none required anticholinesterase. After tracheal extubation, patients were transferred to the postanesthesia care unit (PACU). Postoperative pain was treated with $1-2 \mathrm{mg} \cdot \mathrm{kg}^{-1}$ fentanyl $i p$.

After the children had satisfactorily recovered from the anesthetic and fulfilled routine discharge criteria, they were discharged to the Ambulatory Surgical Unit (ASU) to be reunited with their families. Fluids were offered and encouraged by the nursing staff during the recovery period; however, ingestion of a predetermined volume of oral fluid was not demanded. All episodes of emesis, defined as vomiting or non-productive retching, were recorded in the PACU and the ASU, and parents were contacted by telephone on the day following surgery to determine whether emesis occurred after leaving the hospital. The telephone response rate was $100 \%$. Incidents of nausea alone were not recorded, because it was felt that parents' assessments might be overly subjective. 


\section{Statistical analysis}

The primary endpoint for the study was whether emesis occurred in the $24 \mathrm{hr}$ period following surgery. Our hypothesis predicted that fewer children in the group receiving propofol and ondansetron would experience emesis than in the group receiving propofol plus placebo. The data were analyzed using a onetailed Fisher Exact Test.

From our earlier study we estimated that approximately $25 \%$ of patients undergoing tonsillectomy surgery at our institution with a propofol-based anesthetic would vomit within $24 \mathrm{hr}^{3}$ We predicted that the use of ondansetron in these patients would reduce the incidence of vomiting to $5 \%$. Power analysis showed that approximately 50 children were necessary, in each group, to demonstrate an effect with $\alpha=$ 0.05 and power $=80 \%$. An interim analysis was planned half-way through the study.

\section{Results}

Ninety two patients were enrolled in the study; two were dropped from further analysis because of breaches in the study protocol. The results of 90 patients were analyzed. Forty five patients were randomized to the ondansetron plus propofol group and 45 to the placebo plus propofol group. The age and sex distribution did not vary between the study groups (see Table). The use of bupivacaine did not differ between the groups ( 34 patients in the placebo group and 30 in the ondansetron group; Fisher Exact test). The incidence of mask induction did not differ between groups (six in the placebo group and five in the ondansetron group; Fisher Exact test). The median dose of fentanyl was $2.49 \mu \mathrm{g} \cdot \mathrm{kg}^{-1}$ in the placebo group and $2.37 \mu \mathrm{g} \cdot \mathrm{kg}^{-1}$ in the ondansetron group ( $\left.P: \mathrm{NS}\right)$.

The incidence of emesis was lower in the ondansetron group (6.7\%) than in the placebo group (22.2\%) $(P=0.035$; one-tailed Fisher's Exact Test).

TABLE Comparison of ondansetron and placebo groups

\begin{tabular}{|c|c|c|c|}
\hline Group & $\begin{array}{l}\text { Age }(y r) \\
(\text { mean } \pm S D) \\
(5 \%, 50 \%, 95 \%)\end{array}$ & $\begin{array}{l}\text { Sex } \\
\text { Lale Female }\end{array}$ & $\begin{array}{l}\text { Vomiting } \\
\text { incidence }\end{array}$ \\
\hline
\end{tabular}

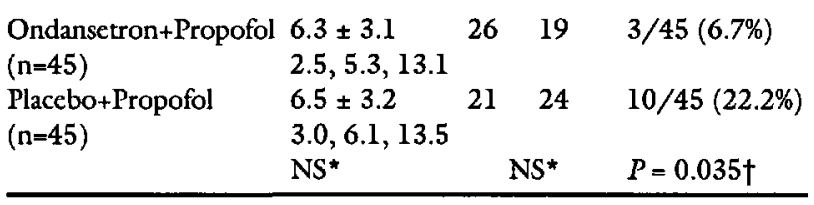

* P. NS (Mann-Whitney Test)

† Fisher Exact test, one-tailed

\section{Discussion}

Many factors contribute to vomiting after tonsillectomy ${ }^{6}$. Blood and mucus in the oropharynx as well as irritation at the tonsillar bed contribute to a gagging sensation. Pain, opioid administration, and swallowed blood are also believed to be contributing factors.

Several recent studies have substantiated the efficacy of various antiemetic agents in the treatment of post- tonsillectomy vomiting. Ferrari and Donlon reduced the incidence of vomiting from $70 \%$ to $47 \%$ by using $0.15 \mathrm{mg} \cdot \mathrm{kg}^{-1}$ metoclopramide. Stene et al. demonstrated similar, though less dramatic results, with a higher dose of metoclopramide $\left(0.25 \mathrm{mg} \cdot \mathrm{kg}^{-1}\right)$ and reported incidences of vomiting of $54 \%$ in their treatment group and $69 \%$ in the control group. ${ }^{8}$ Stene and colleagues also investigated the efficacy of ondansetron in preventing post- tonsillectomy emesis and reported an incidence of $26 \%$. This result is comparable to data reported by Litman $e t a l .^{4}$ who demonstrated that $0.15 \mathrm{mg} \cdot \mathrm{kg}^{-1}$ ondansetron reduced the incidence of vomiting from $73 \%$ to $23 \%$. Similar results were obtained by Furst and Rodarte who reported a decrease in post-tonsillectomy vomiting from $62 \%$ to $27 \%{ }^{5}$ In each of these studies, the primary anesthetic agent was either halothane or isoflurane. These studies differed in several respects: exclusion of patients with a history of motion sickness; use of non-depolarizing muscle relaxants; different opioid analgesic regimens and whether the patients' stomachs were emptied at the conclusion of the procedure. Interestingly, despite the differences in the experimental protocols these studies had similar incidences of vomiting in their control and treatment groups.

We reported a decrease from $55 \%$ to $21 \%$ in posttonsillectomy vomiting by utilizing a propofol-based anesthetic instead of a gaseous agent, and without utilizing antiemetic agents. ${ }^{3}$ This incidence of post-operative vomiting was as low as any reported by those centres utilizing ondansetron. Ved $e t a l^{l}$ also demonstrated a $70 \%$ decrease in post-operative vomiting in patients who received propofol as a primary anesthetic as opposed to patients in a halothane control group. Nevertheless, those authors-found no difference in rates of vomiting between the propofol and halothane groups beyond six hours.

In our patients, the anti-emetic effect of propofol was observed for at least $24 \mathrm{hr}$. Again, differences in study design, including use of opioids or muscle relaxants, may account for some of the discrepancy between our result and that of Ved $e t a l$. The fact that our two consecutive studies yielded virtually identical incidences of vomiting in the propofol group, $21 \%$ and $22 \%$, confirms the internal validity of our methods 
and, we believe, further affirms the inherent antiemetic effects of propofol. It is clear that, with concurrent use of propofol and ondansetron, post tonsillectomy emesis can be reduced in children to very low levels.

\section{References}

1 Ved SA, Walden TL, Montana J, et al. Vomiting and recovery after outpatient tonsillectomy and adenoidectomy in children. Comparison of four anesthetic techniques using nitrous oxide with halothane or propofol. Anesthesiology 1996; 85: 4-10.

2 Carithers JS, Gebbart DE, Williams JA. Postoperative risks of pediatric tonsilloadenoidectomy. Laryngoscope 1987; 97: 422-9.

3 Barst SM, Markowitz A, Yossefy $Y$, Abramson $A$, Lebowitz $P$, Bienkowski RS. Propofol reduces the incidence of vomiting after tonsillectomy in children. Paediatr Anaesth 1995; 5: 249-52.

4 Litman RS, Wu CL, Catanzaro FA. Ondansetron decreases emesis after tonsillectomy in children. Anesth Analg 1994; 78: 478-81.

5 Furst $S A$, Rodarte A. Prophylactic antiemetic treatment with ondansetron in children undergoing tonsillectomy. Anesthesiology 1994; 81: 799-803.

6 Watcha MF, White PF. Postoperative nausea and vomiting. Its etiology, treatment, and prevention. Anesthesiology 1992; 77: 162-84.

7 Ferrari LR, Donlon JV. Metoclopramide reduces the incidence of vomiting after tonsillectomy in children. Anesth Analg 1992; 75: 351-4.

8 Stene EN, Seay RE, Young LA, Bobnsack LE, Bostrom BC. Prospective, randomized, doubleblind, placebo- controlled comparison of metoclopramide and ondansetron for prevention of posttonsillectomy or adenotonsillectomy emesis. J Clin Anesth 1996; 8: 540-4. 